\title{
Experience of using home-based fortified diet in rehabilitation of malnourished children at Indus Hospital, Karachi, Pakistan: an institution based retrospective chart review study
}

\author{
Saba Shahid ${ }^{1 *}$, Marvi Mahesar ${ }^{2}$, Anum Rahim $^{3}$ and Yumna Sadiq ${ }^{4}$
}

\begin{abstract}
Background: Globally, it is estimated that 50 million children under five are wasted. National nutrition survey-2018 has shown that 23.3 and $45.5 \%$ of children are wasted and stunted in Pakistan. Many studies have shown that hospital-based management of malnutrition is not practical due to high cost and iatrogenic infections and currently WHO recommends community-based management of malnutrition with provision of therapeutic food. There is limited evidence of community rehabilitation of malnourished children by using home fortified diet in Pakistan. This study explores use of energy dense, home fortified diet in achieving weight gain of malnourished children in Karachi.

Methods: A descriptive, retrospective chart review of pediatric patients (aged 6 month-5 years) seen in Indus Hospital between January 2017 to June 2018 was conducted. A pre-designed data abstraction form was used to record detailed information about demographic characteristics, feeding, anthropometric, micronutrient, and nutritional details at enrollment and on follow-up.

Results: A total of 361 patients were included in the final analysis. The median age (IQR) of children was 15 (14) months. Forty eight percent $(n=172)$ children had diarrhea and 54\% $(n=195)$ children had respiratory tract infection. The median length of stay in the program was 28 days. The median (IQR) for average weight gain was 4.8 $(0-10.3) \mathrm{g} / \mathrm{Kg} /$ day, $64.6 \%(n=226)$ children defaulted, 29\% $(n=102)$ were cured and $3 \%(n=10)$ died.

Conclusion: This study showed adequate weight gain and recovery in malnourished children by using home fortified diet in real life situations without using therapeutic food or monetary support. Home fortified diets may serve as effective strategy in community-based rehabilitation of malnourished children.
\end{abstract}

Keywords: Malnutrition, Children, Home fortified diet, Weight gain, Anemia, And rickets

\footnotetext{
* Correspondence: saba.shahid@tih.org.pk

${ }^{1}$ Department of Pediatrics, The Indus Hospital, Karachi City, Pakistan

Full list of author information is available at the end of the article
}

(c) The Author(s). 2021 Open Access This article is licensed under a Creative Commons Attribution 4.0 International License, which permits use, sharing, adaptation, distribution and reproduction in any medium or format, as long as you give appropriate credit to the original author(s) and the source, provide a link to the Creative Commons licence, and indicate if changes were made. The images or other third party material in this article are included in the article's Creative Commons licence, unless indicated otherwise in a credit line to the material. If material is not included in the article's Creative Commons licence and your intended use is not permitted by statutory regulation or exceeds the permitted use, you will need to obtain permission directly from the copyright holder. To view a copy of this licence, visit http://creativecommons.org/licenses/by/4.0/. The Creative Commons Public Domain Dedication waiver (http://creativecommons.org/publicdomain/zero/1.0/) applies to the data made available in this article, unless otherwise stated in a credit line to the data. 


\section{Background}

Malnutrition can be defined as a state of nutrition in which there may be excess or deficiency of calories, nutrients and proteins. Malnutrition can adversely affect normal growth, and clinical outcomes of sick children.

It was estimated that in year 2019, one hundred and forty-four million children under five were wasted globally and South Asia was the epicenter of the global burden [1]. National nutrition survey-2018 of Pakistan also reflects high burden of malnutrition in children under 5 years. Around 23.3 and $45.5 \%$ of children are wasted and stunted in Pakistan and highest rate of malnutrition is reported from Sindh province [2].

WHO initially advocated management of malnourished children in hospitals [3]. However inpatient management did not prove to be practical due to several constraints which included high cost of management, iatrogenic infections and cost to families due to prolonged hospital stay [4] Due to these challenges, WHO revised treatment guidelines and recommended that only complicated malnourished children should be treated in hospitals while uncomplicated cases should be managed in community-based settings [3]. In order to ensure optimal diet for community management, in resourcerestrained countries UNICEF recommended either use of therapeutic diets like Ready to use therapeutic feed (RUTF) [5] and Corn Soya Blend (CSB) [6] or fortification of local diet with products like Micro Nutrient Powder (MNP) [7].

Products like therapeutic feed are costly. They depend on import of ingredients and presence of infrastructure for their manufacture. In Pakistan, government-run programs supply local or international produced RUTF to selected rural and urban areas [8-11]. However, the supply of RUTF is erratic and selective as a result, many urban and rural areas remain deprived of nutritional supplements. The caregivers in areas where there is no RUTF supplementation rely on unfortified indigenous food products for feeding children, which results in lack of dietary diversity and acceptable diet remains less than recommended values [2].

One logical, cost effective and feasible method of improving the quality and nutritive value of complementary food in Pakistani households is to fortify the existing recipes with locally available nutri-dense products [8]. These fortified home diets may act as surrogate for commercial therapeutic feeds and may provide a cost effective and convenient solution for nutritional rehabilitation in LMIC. We feel that feasibility, of using of fortified; home-based foods, should be checked in real life situations without giving monetary incentives to the caregivers. .

Therefore, this study aims to explore use of energy dense, home fortified diet in achieving weight gain in malnourished children through a descriptive, retrospective chart review study. The primary objective of the study was to determine cure from malnutrition on basis of weight for height standard deviation (SD) score and mid upper arm circumference (MUAC) measurement. The secondary outcomes included weight gain in $\mathrm{g} / \mathrm{Kg} /$ day, average stay in nutrition program, and recovery from micronutrient deficiencies which include anemia, rickets and vitamin B12 deficiency, default rate and mortality.

\section{Methods}

\section{Study area and period}

Institution based descriptive, retrospective chart review was conducted from January 2017 to June 2018. The study was conducted at The Indus Hospital, which is a tertiary care facility in the suburbs of Karachi, Pakistan. Around 1200-1300 malnourished children are seen annually in this hospital, which include a mix of severe acute malnutrition (SAM) and moderate acute malnutrition (MAM). Community based rehabilitation of uncomplicated malnourished children is done in outpatient department of Indus Hospital by counseling and recommendation of fortified home-based staple diet plans with regular follow up.

\section{Sample size and sampling procedure}

\section{Sample size determination}

The sample size was computed using OpenEpi version 3.01 Statistical software with the following assumptions: Proportion of children attained desired weight using home based fortified diet as 69\% [9], confidence level of $95 \%$ with $5 \%$ margin of error. The minimum required sample size required for the study was 329 children.

\section{Inclusion criteria}

All children with ages ranging from 6 to 59 months with malnutrition, who were treated at Indus nutrition rehabilitation clinic (NRC), from January 2017 to June 2018 were included in the study.

\section{Exclusion criteria}

Children who did not have proper records were excluded from the study. Children with secondary malnutrition due to other medical conditions or children who had edema due to other causes were also excluded from the study.

\section{Treatment protocol}

Nutrition rehabilitation clinic (NRC) was conducted twice weekly in the outpatient department of Indus Hospital. The clinic catered to malnourished children with ages ranging from 6 month- 5 years. Malnutrition was 
diagnosed on basis of weight, height and mid upper arm circumference cut-off values prescribed by WHO. At enrollment nutritional details of each child were recorded on pilot tested, predesigned questionnaire which included nutritional history and details of physical examination. Examination was done for anthropometry and clinical features like edema, dermatosis, anemia, rickets and eye changes. If there were clinical signs of micronutrient deficiencies, then relevant labs were sent. Children with rickets and anemia were treated with oral iron and vitamin D3 supplements. The dosages of iron and vitamin $\mathrm{D}$ were prescribed according to WHO protocols. Blood transfusion was done in cases of severe anemia. Vitamin B12 deficiency was treated with oral Cobalamin according to institutional protocol. All the malnourished children were given multiple micronutrient powder (MNP) and zinc supplements. Antibiotics were given when needed.

Mothers were counseled on age appropriate feeding practices and hygiene strategies through Infant young child feeding practices (IYCF) counseling cards.. The diet plans were made by the nutritionist at Indus hospital using ingredients which were indigenous and available in normal households. Cooking of fortified recipes was demonstrated to the mothers in the cooking area. Quantities of the ingredients were shown by using spoon and measuring cups. After demonstration of recipes, brochures containing pictorial and written instructions in Urdu were $\mathrm{f}$ given to the mothers for reminder at home. Meal frequencies ranging from 2 to 6 times per day were advised based on age of child. For non-breast-fed children milk and milk products were added. About $150-220 \mathrm{Kcal} / \mathrm{kg} /$ day of calories and $3-5 \mathrm{~g} / \mathrm{kg} /$ day of proteins were advised. Calories and proteins were gradually escalated in the diet.

Children were regularly followed according to severity of malnutrition. Moderately malnourished children were followed 3 weekly whereas severely malnourished children were called fortnightly. At every follow up visit mothers were asked about cooking techniques, re-counseling by the nutritionists was done if there was any variation in recipe or cooking method. Height, weight and MUAC were recorded at every follow up visit. Weight gain was calculated on basis of weight for height ratio and MUAC cutoffs. Adequate weight gain was considered when weight for height/length Z-score was equal or more than 1 standard deviation or MUAC was more than 12.5 cms. Absenteeism from follow up for more than $\mathrm{r} 6$ consecutive weeks was considered as default. The children after recovery were followed for 2 months to ensure continuous weight gain.

\section{Operational definition}

Severe acute malnutrition (SAM)

SAM was labeled if any of the three criteria was present (i) weight for height/length Z- score $<-3.0$, or (ii) mid upper arm circumference $<11.5 \mathrm{~cm}$, or (iii) pitting pedal edema [3].

\section{Moderate acute malnutrition (MAM)}

MAM was labeled when weight for height/length Zscore was $<-2.0$, or $(i i)$ mid upper arm circumference was between $11.5-12.5 \mathrm{~cm} \mathrm{[3].}$

\section{Anemia}

Severe when hemoglobin is less than $6 \mathrm{~g} / \mathrm{dl}$ and moderate when hemoglobin level is between 6.1-11 $\mathrm{g} / \mathrm{dl}$ [3].

\section{Vitamin B12 deficiency}

Plasma vitamin B 12 level < 203 pg/mL [12].

\section{Rickets}

Serum $25(\mathrm{OH})$ D levels at $<30 \mathrm{nmol} / \mathrm{L}$ with or without clinical signs of Rickets [13].

\section{Weight gain}

Weight gain was calculated in $\mathrm{g} / \mathrm{Kg} /$ day. $5 \mathrm{~g} / \mathrm{kg} /$ day is considered adequate weight gain [14].

\section{Edema}

Presence of pitting edema on dorsum of feet or shin of legs or peri-orbital edema.

\section{Cure}

Child was considered cured when weight for height/ length SD score was >-1.0 SD, or mid upper arm circumference was $>12.5 \mathrm{~cm}$, whichever came first.

\section{Data collection procedure}

A structured data extraction form was used for data collection. Data were gathered for demographic characteristics, feeding, and micronutrient, anthropometric and nutritional details at enrollment and on follow-up. Data were collected by nutritionists and doctor. The data extraction form was adopted from WHO guidelines [3] and Sphere standard for management of severe acute malnutrition [14].

\section{Data management and analysis}

The statistical analysis was performed using Stata 16.0 software. Normality assessment of continuous variables was done on the basis of skewness and kurtosis. Normally distributed variables were reported as mean [SD] whereas median (IQR) was calculated for skewed variables. Paired $\mathrm{T}$ test was applied to compare the entry and exit variables for normally distributed variables, 
while Wilcoxon sign rank test was used for non-normal data. The categorical data was presented as frequencies and percentages. McNemars test was applied to measure the difference between $(2 \times 2)$ variables, whereas others with more than two categories were assed via McNemars Bowker test. $P$ value $<0.05$ was considered to be significant.

\section{Results}

\section{Participants}

A total of 490 children were screened for malnutrition. Out of these, 129 were excluded initially due to various reasons which included presence of only micronutrient deficiencies and presence of chronic illness which could have affected clinical outcome. The data for the remaining 361 patients were further analyzed (Fig. 1).

The median age of children was 14 (IQR 15) months. More than half of children were female $(53.5 \%, n=193)$.
Maximum numbers of children were residents of Korangi $48.9 \%(n=175)$ district. Diarrhea and respiratory tract infections were most common infections, $52.8 \%$ $(n=161)$ children had diarrhea and $51.7 \%(n=182)$ children had respiratory tract infection at time of enrollment. Of the 361 patients, malnutrition was identified in $97 \%$ children $(n=353)$ on basis of MUAC. Weight for height measurement identified $40 \%(n=145)$ children with malnutrition (Table 1).. Eleven of the enrolled children left without initiation of treatment, thereby excluded from the final analysis (Fig. 1).

\section{Analysis of primary outcomes}

Out of the 350 children included in the final analysis, 64.6\% $(\mathrm{n}=226)$ were defaulters, $29 \%(\mathrm{n}=102)$ achieved adequate weight gain, $3.4 \%(n=12)$ continued with the treatment and 3\% $(n=10)$ died (Fig. 1 \& Table 2).

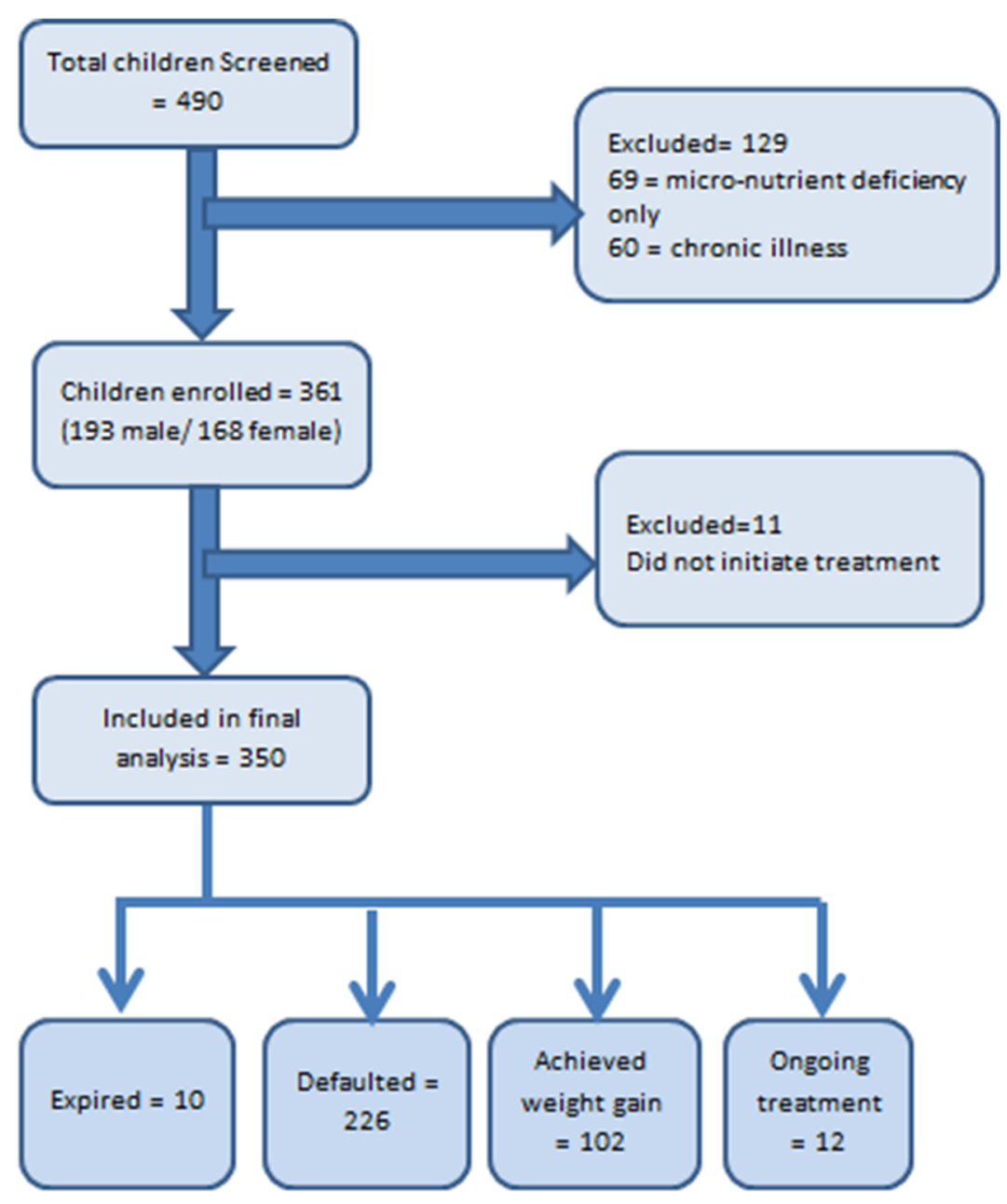

Flow chart of patients' enrolment and outcome

Fig. 1 Flow-chat of patients' enrolment and outcome 
Table 1 Baseline characteristics of children

\begin{tabular}{|c|c|c|c|}
\hline Variables & & Frequency & Percent \\
\hline Age of child* (359) & $6-59$ & 14 & 15 \\
\hline \multirow[t]{7}{*}{ District (358) } & West & 7 & 2.0 \\
\hline & East & 18 & 5.0 \\
\hline & Central & 8 & 2.2 \\
\hline & South & 9 & 2.5 \\
\hline & Malir & 107 & 29.9 \\
\hline & Korangi & 175 & 48. \\
\hline & Other & 34 & 9.5 \\
\hline \multirow[t]{2}{*}{ Sex (361) } & Male & 168 & 46.5 \\
\hline & Female & 193 & 53.5 \\
\hline \multirow[t]{3}{*}{ Type of feeding (134) } & Exclusive breast feeding & 48 & 35.8 \\
\hline & Top feeding & 66 & 49.3 \\
\hline & Combination feeding & 20 & 14.9 \\
\hline \multirow[t]{2}{*}{ Vitamin D deficiency (218) } & Present & 116 & 53.2 \\
\hline & Absent & 102 & 46.8 \\
\hline \multirow[t]{2}{*}{ Anemia (253) } & Present & 12 & 4.9 \\
\hline & Absent & 233 & 95.1 \\
\hline \multirow[t]{2}{*}{ Vitamin A deficiency (245) } & Present & 12 & 4.9 \\
\hline & Absent & 233 & 95.1 \\
\hline \multirow[t]{2}{*}{ Dermatosis (347) } & Present & 9 & 2.6 \\
\hline & Absent & 338 & 97.4 \\
\hline \multirow[t]{2}{*}{ Edema (349) } & Present & 21 & 6.0 \\
\hline & Absent & 328 & 94.0 \\
\hline \multirow[t]{2}{*}{ Otitis media (344) } & Present & 5 & 1.5 \\
\hline & Absent & 339 & 98.6 \\
\hline \multirow[t]{2}{*}{ Respiratory tract infection(352) } & Present & 182 & 51.7 \\
\hline & Absent & 170 & 48.3 \\
\hline \multirow[t]{2}{*}{ Diarrhea (305) } & Present & 161 & 52.8 \\
\hline & Absent & 144 & 47.2 \\
\hline \multirow[t]{3}{*}{ MUAC at enrolment(357) } & Normal & 4 & 1.1 \\
\hline & MAM & 104 & 29.1 \\
\hline & SAM & 249 & 69.8 \\
\hline \multirow[t]{3}{*}{ Weight for height SD score at enrolment(160) } & Normal & 15 & 9.4 \\
\hline & MAM & 51 & 31.9 \\
\hline & SAM & 94 & 58.8 \\
\hline
\end{tabular}

${ }^{*}$ Median (IQR)

Over all 102 patients achieved adequate weight gain. Of these, $75.5 \%(n=77)$ were considered to be cured on the basis of MUAC, while 20\% $(n=20)$ were considered to be cured on the basis of weight for height SD score and $5 \%(n=5)$ were cured on the basis of both (Table 2). There was significant difference ( $p$ value $=0.00)$ in the number of patients who were cured on the basis of MUAC and weight for height SD score (Table 3).

\section{Analysis of secondary outcomes}

The median (IQR) stay in the program was 28 days (101). The median weight gain was $4.8(\mathrm{IQR}=10.3) \mathrm{g} /$ $\mathrm{Kg} /$ day (Table 2). Two hundred and twenty six children (65\%) did not follow up in the OPDs regularly out of which $73 \%(n=263)$ never came after initial visit while 22 children (6\%) came for 3 visits, (Table 2). There was no significant difference between males and females in the number of defaults during follow-ups. Children who 
Table 2 Outcomes at completion of study

\begin{tabular}{lll}
\hline Variables & Frequency & Percent \\
\hline Duration of stay in the program* (302) & 28 & 101 \\
Weight gain g/Kg/day* (181) & 4.8 & 10.3 \\
No of follow-ups & & \\
0 & 263 & 72.9 \\
1 & 56 & 15.5 \\
2 & 20 & 5.5 \\
3 & 22 & 6.1 \\
Infection developed during treatment (98) & 39 & 39.8 \\
Cure on basis of anthropometry (102) & & \\
MUAC & 77 & 75.5 \\
Weight for height SD score & 20 & 19.6 \\
Both & 5 & 4.9 \\
Outcome status (350) & & \\
defaulter & 226 & 64.6 \\
achieved adequate weight gain & 102 & 29.1 \\
expired & 10 & 2.9 \\
Ongoing & 12 & 3.4 \\
\hline *Median (IQR) & &
\end{tabular}

came for maximum number of follow ups belonged to Korangi district; $49 \%(n=175)$. While children belonging to district West $2 \%(n=7)$ had least number of follow-ups (Fig. 2).

There was significant difference in anemia and vitamin $D$ status of the patients at the time on enrolment compared to the time of exit. Twenty-four children (6.8\%) had severe anemia at time of enrollment which had reduced to 3 children (3\%) at time of exit ( $p$-value: 0.00 ). Vitamin D deficiency was observed in 101 children (53\%) at enrollment while at exit 5 children (17\%) had vitamin D deficiency (p-value: 0.04 ). Recovery from vitamin B12 and Folate deficiency were not statistically significant. Forty-nine children (32\%) had vitamin B12 deficiency, out of which 45 children got cured (p-value: 1.0). Five children had Folate deficiency, and all got cured (p-value: 1.0) (Table 3).

\section{Discussion}

This study analyzed efficacy of using fortified, energy dense, home prepared diet, in rehabilitation of uncomplicated malnourished children, aged 6 to 59 months, treated in a tertiary care hospital. Findings of this study showed that median age of children was 15 months. Out of 350 children whose final outcome was known, 65\% $(n=226)$ were defaulters, $29 \%(n=102)$ achieved adequate weight gain and $2.9 \%(\mathrm{n}=10)$ died. The average stay in nutrition rehabilitation program was 28 days. The average weight gain of the children was $4.8 \mathrm{~g} / \mathrm{kg} /$ day.
Table 3 Comparison of nutritional status at entry and exit of nutrition program

\begin{tabular}{|c|c|c|c|}
\hline \multirow[t]{2}{*}{ Characteristics } & \multicolumn{2}{|c|}{ Nutritional status } & \multirow[t]{2}{*}{ P-value } \\
\hline & At entry (\%) & At exit (\%) & \\
\hline \multicolumn{4}{|c|}{ Nutritional status based on MUAC } \\
\hline Normal & $4(1.1)$ & $82(30.7)$ & $0.00^{¥}$ \\
\hline SAM & $104(29.1)$ & $71(26.6)$ & \\
\hline MAM & $249(69.8)$ & $114(42.7)$ & \\
\hline
\end{tabular}

Nutritional status based on weight for height SD score

$\begin{array}{llll}\text { Normal } & 15(9.4) & 25(37.3) & 0.00 \\ \text { SAM } & 51(31.9) & 26(38.8) & \\ \text { MAM } & 94(58.8) & 16(23.9)\end{array}$

\begin{tabular}{|c|c|c|c|}
\hline \multicolumn{4}{|c|}{ Anemia (on basis of hemoglobin) } \\
\hline Normal & $56(15.9)$ & $23(21.5)$ & $0.00^{*}$ \\
\hline Mild Anemia & $74(21)$ & $26(24.3)$ & \\
\hline Moderate & $198(56.3)$ & $55(51.4)$ & \\
\hline Severe Anemia & $24(6.8)$ & $3(2.8)$ & \\
\hline \multicolumn{4}{|c|}{ Vitamin D (on basis of $25(0 \mathrm{H}) \mathrm{D}$ level) } \\
\hline Normal & $88(46.6)$ & $24(82.8)$ & $0.04^{n}$ \\
\hline Deficient & $101(53.4)$ & $5(17.2)$ & \\
\hline \multicolumn{4}{|l|}{ Folate } \\
\hline Normal & $54(91.5)$ & $11(100)$ & $1.00^{\natural}$ \\
\hline Deficient & $5(8.5)$ & $0(0)$ & \\
\hline \multicolumn{4}{|c|}{ B 12 (on basis of serum levels) } \\
\hline Normal & $104(68)$ & $34(89.5)$ & $1.00^{\natural}$ \\
\hline Deficient & $49(32)$ & $4(10.5)$ & \\
\hline Height* & $69(63-74.3)$ & $72(60-77)$ & $0.00^{\epsilon}$ \\
\hline Weight & $6.2(1.7)$ & $7.1(1.8)$ & $0.00^{\top}$ \\
\hline
\end{tabular}

Mcnemar bowker test (¥),McNemars (ף),Wilcoxon signed rank test (€), Paired $T$ test $(D)$, Median $(I Q R)^{*}$.

In our study we were able to achieve weight gain more than $4 \mathrm{~g} / \mathrm{kg} /$ day, which is WHO minimum standard for community treatment of malnourished children [15]. We did not achieve good weight gain $(5-10 \mathrm{~g} / \mathrm{Kg} /$ day), which is stated to be in range of $5-10 \mathrm{~g} / \mathrm{kg} /$ day according to SPHERE standards [14]. The low weight gain in our study could be because of multiple factors, which may include lack of mothers' compliance in preparation of recipes, in- frequent feeding of children, food sharing at home and unhygienic feeding practices. An additional explanation of slow weight gain in our study could be high rate of infections both at enrollment and follow up. We observed that 54 and $48 \%$ children had respiratory tract infections and diarrhea respectively. The infections could be due poor hygienic conditions and incomplete vaccination status of the children in our study.

Several studies have shown weight gain ranging from $1.7 \mathrm{~g} / \mathrm{kg} /$ day to $8.7 \mathrm{~g} / \mathrm{kg} /$ day with use of therapeutic, fortified diet [16-20]. However most of these studies [2-5] 


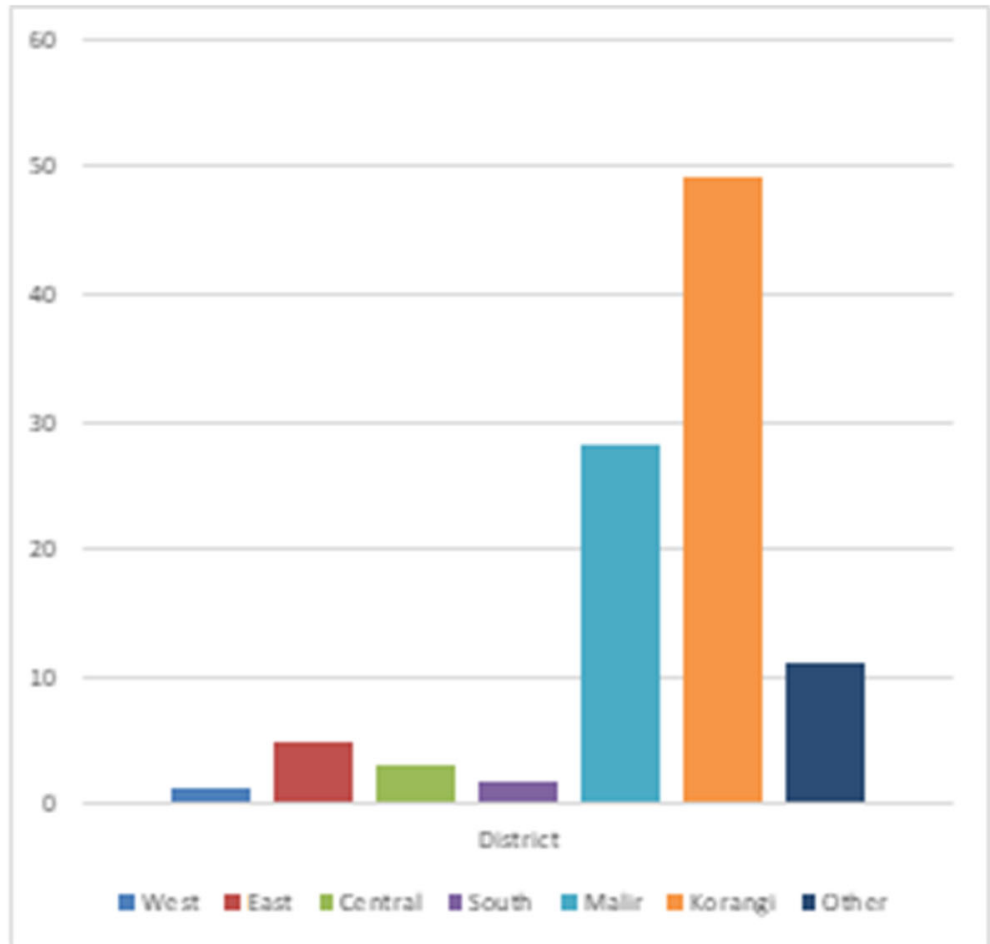

\section{Percentage of district distribution of the defaulted children}

Fig. 2 Percentage of district distribution of the defaulted children

were done in controlled environment, where therapeutic nutrition supplements were given to the children free of cost and regular monitoring through home visits were done. We conducted this study in real life situation without any external monetary funding or food support and there were no home visits, this may have contributed to slow weight gain. We measured height and weight in every follow up and used height recorded in the last follow up for calculating final WHZ score. This was done to ensure accuracy but this method shows slow recovery from malnutrition [21] and could be a contributing factor for slow weight gain in our children.

We observed high default rate, 226 (64.6\%) children did not come for regular follow ups despite frequent telephonic reminders. Aguayo and colleagues [22] also reported default rate of $11 \%$ while assessing community rehabilitation of malnutrition in Pakistan. In our study many children who defaulted, resided in close proximity to our hospital. We observed that many defaulted children continued to have infections till their last follow up. There is a possibility that parents considered infections as poor recovery and stopped coming to hospital due to this reason. Parents' lack of understanding about adverse consequences of malnutrition in their children can be another reason for default. Baig and Mahmood have reported that parents living in urban settlements of Pakistan lack awareness about importance of nutrition due low education $[23,24]$. We need further studies to determine reasons for default in hospital visits of malnourished children.

World Health Organization [15] recognizes that there is difference in group of children recognized by midupper-arm circumference (MUAC) and weight-forheight Z-scores (WHZ) WHO estimated that there is $40 \%$ overlap between the two indicators in identifying malnutrition [25]. We also observed difference between MUAC and WHZ scores. Seventy-seven children were cured on basis of MUAC and 20 children were cured on basis of WHZ. Grellety and Golden [26] collected data on these 2 variables from 47 countries and found out that both criteria identify different sets of malnourished children but these 2 criteria are complimentary to each other in identifying risks of mortality. Relying on one criterion may under detect cases and deny treatment to children who are at risk of dying from malnutrition related complications. The author recommended that both MUAC and WHZ should be used in nutrition programs to prevent risk of mortality and under detection of cases.

The results of our study showed that by using home fortified diet, we were able to achieve weight gain in $29 \%$ 
children. Weight gain of $4.8 \mathrm{~g} / \mathrm{Kg} /$ day was observed. This result has important practical implication as it shows that home fortified diets if combined with robust community monitoring, can be used in place of commercially available RUTF.

\section{Strengths and limitations of the study}

To the best of our knowledge, this is first study done in Pakistan which has assessed efficacy of home-based fortified diet in rehabilitation of malnourished children in real life situation without provision of food or financial support. This has important operational implications as many therapeutic nutrition centers in urban areas of Pakistan currently do not provide RUTF or offer home monitoring of children. We used both MUAC and WHZ for enrolment and exit which minimized risk of under detection of malnourished children.

We had some limitations due to a retrospective nature of study. These include missing records in some outcome variables. We were unable to capture important socio-demographic information like parental education and household details due to insufficient data available in files. The available information had several missing values; therefore the regression analysis was not performed.

\section{Conclusion}

This study revealed adequate weight gain and recovery in malnourished children by using home fortified diet in real life situations without using therapeutic food or monetary support. These findings may have implications for planning future nutrition programs in Pakistan, especially in urban areas. We, therefore, recommend that robust community reach out programs, using home fortified diet and effective nutritional counseling should be implemented for rehabilitation of malnourished children.

\footnotetext{
Abbreviations

National nutrition survey-2018: (5); WHO: World Health Organization; SAM: severe acute malnutrition; MAM: moderate acute malnutrition; UNICEF: United Nation Children's Fund; RUTF: Ready to use therapeutic feed; CSB: Corn Soya Blend; MNP: Micro Nutrient Powder; IYCF: Infant young child feeding practice
}

\section{Acknowledgements}

Not applicable.

\section{Authors' contributions}

SS and MM conceived idea of the study and participated in study design and write up. YS carried out data collection and helped in write up. MM and AR assisted with statistical analysis. All authors were involved in the coordination of the study, drafting the manuscript and approving the final version.

\section{Funding}

No funding was received for this research.

\section{Availability of data and materials}

The data used in this study was retrieved from the Indus Hospital management information system, with due permission. The datasets used and/or analyzed during the current study are available from the corresponding author on reasonable request.

\section{Declarations}

Ethics approval and consent to participate

Ethical approval was taken from the Institutional Review Board (IRB) of Interactive Research \& Development, registered with the U.S. Department of Health and Human Services, Office for Human Research Protections at The Indus Hospital. The approval included a written permission from the IRB, as a part of the Indus Hospital, to retrieve patient data from the hospital management information system for the purpose of this study. As the study data was a retrospective chart review, without direct interaction with patients or their caregivers, therefore, the IRB waived off the requirement of written informed consent from study participants.

\section{Consent for publication}

Not applicable.

\section{Competing interests}

The authors declare that they have no competing interests.

\section{Author details}

'Department of Pediatrics, The Indus Hospital, Karachi City, Pakistan. ${ }^{2}$ Indus Hospital Research Center, The Indus Hospital, Karachi City, Pakistan. ${ }^{3}$ Indus Hospital Research Center, The Indus Hospital, Karachi City, Pakistan. ${ }^{4}$ Nutrition and Food Services Department, The Indus Hospital, Karachi City, Pakistan.

Received: 17 August 2020 Accepted: 7 July 2021

Published online: 13 August 2021

\section{References}

1. Organization WH. UNICEF/WHO/the World Bank Group joint child malnutrition estimates: levels and trends in child malnutrition: key findings of the 2020 edition. 2020.

2. UNICEF GoPa. National Nutrition Survey 2018 - Key Findings Report 2019. Available from: https://www.unicef.org/pakistan/reports/national-nutritionsurvey-2018-key-findings-report.

3. Organization WH. Management of severe malnutrition: a manual for physicians and other senior health workers. World Health Organization; 1999.

4. Studies NloP, Demographic MllfRD, Surveys H. Pakistan Demographic and Health Survey. National Institute of Population Studies; 2012.

5. Collins S, Dent N, Binns P, Bahwere P, Sadler K, Hallam A. Management of severe acute malnutrition in children. Lancet. 2006;368(9551):1992-2000. https://doi.org/10.1016/S0140-6736(06)69443-9.

6. Dewey KG. Formulations for fortified complementary foods and supplements: review of successful products for improving the nutritional status of infants and young children. Food Nutr Bull. 2009;30(2_suppl2): S239-S55.

7. De-Regil LM, Suchdev PS, Vist GE, Walleser S, Peña-Rosas JP. Home fortification of foods with multiple micronutrient powders for health and nutrition in children under two years of age. Evidence Based Child Health. 2013:8(1):112-201. https://doi.org/10.1002/ebch.1895.

8. Ahmed T, Hossain M, Mahfuz M, Choudhury N, Hossain MM, Bhandari N, et al. Severe acute malnutrition in Asia. Food Nutr Bull. 2014;35(2_suppl1): S14-26.

9. Akram DS, Arif F, Khan DS, Samad S. Community based nutritional rehabilitation of severely malnourished children. JPMA. 2010;60(3):179-81.

10. De Bustos C, Basquin C, Rudert C. Severe acute malnutrition: an unfinished agenda in East Asia and the Pacific. Field Exchange. 2016;52(6):93.

11. Akram D-S, Suleman Y, Hanif HM. Home-based rehabilitation of severely malnourished children using indigenous high-density diet. J Pak Med Assoc. 2016;66(3):251-5.

12. de Benoist B. Conclusions of a WHO Technical Consultation on folate and vitamin B12 deficiencies. Food Nutr Bull. 2008;29(2_suppl1):S238-S44. 
13. Greer FR. Defining vitamin D deficiency in children: beyond $25-\mathrm{OH}$ vitamin D serum concentrations. Pediatrics. 2009;124(5):1471-3. https://doi.org/10.1 542/peds.2009-2307.

14. Charter H. Minimum standards in humanitarian response. In: sphere handbook. 2018.

15. WHO W, UNSCN U. Community-based Management of Severe Acute Malnutrition: a joint statement by the World Health Organization, the world food Programme, the United Nations system standing committee on nutrition and the United Nations Children's fund. Geneva: World Health Organization, World Food Programme, United Nations System Standing Committee on Nutrition, United Nations Children's Fund; 2007.

16. Dani V, Satav K, Pendharkar J, Satav A, Ughade S, Adhav A, et al. Community-based management of severe malnutrition: SAM and SUW in the tribal area of Melghat, Maharashtra, India. Clin Epidemiol Glob Health. 2017:5(2):62-9. https://doi.org/10.1016/j.cegh.2016.11.003.

17. Bhandari N, Mohan SB, Bose A, lyengar SD, Taneja S, Mazumder S, et al. Efficacy of three feeding regimens for home-based management of children with uncomplicated severe acute malnutrition: a randomised trial in India. BMJ Global Health. 2016;1(4):1-14.

18. Thakur GS, Singh H, Patel C. Locally-prepared ready-to-use therapeutic food for children with severe acute malnutrition: a controlled trial. Indian Pediatr. 2013:50(3):295-9. https://doi.org/10.1007/s13312-013-0097-x.

19. Burza S, Mahajan R, Marino E, Sunyoto T, Shandilya C, Tabrez M, et al. Community-based management of severe acute malnutrition in India: new evidence from Bihar. Am J Clin Nutr. 2015;101(4):847-59. https://doi.org/10.3 945/ajcn.114.093294.

20. Patel D, Gupta P, Shah D, Sethi K. Home-based rehabilitation of severely malnourished children in resource poor setting. Indian Pediatr. 2010;47(8): 694-701. https://doi.org/10.1007/s13312-010-0102-6.

21. Berkley J, Mwangi I, Griffiths K, Ahmed I, Mithwani S, English M, et al. Assessment of severe malnutrition among hospitalized children in rural Kenya: comparison of weight for height and mid upper arm circumference. Jama. 2005;294(5):591-7. https://doi.org/10.1001/jama.294.5.591.

22. Aguayo VM, Badgaiyan N, Qadir SS, Bugti AN, Alam MM, Nishtar N, et al. Community management of acute malnutrition (CMAM) programme in $\mathrm{P}$ akistan effectively treats children with uncomplicated severe wasting. Matern Child Nutr. 2018:14:e12623.

23. Baig-Ansari N, Rahbar MH, Bhutta ZA, Badruddin SH. Child's gender and household food insecurity are associated with stunting among young Pakistani children residing in urban squatter settlements. Food Nutr Bull. 2006;27(2):114-27. https://doi.org/10.1177/156482650602700203.

24. Mahmood S, Nadeem S, Saif T, Mannan M, Arshad U. Nutritional status and associated factors in under-five children of Rawalpindi. J Ayub Med Coll Abbottabad. 2016:28(1):67-71.

25. Organization WH. WHO child growth standards and the identification of severe acute malnutrition in infants and children: joint statement by the World Health Organization and the United Nations Children's fund. 2009

26. Grellety E, Golden MH. Weight-for-height and mid-upper-arm circumference should be used independently to diagnose acute malnutrition: policy implications. BMC nutrition. 2016;2(1):10. https://doi.org/10.1186/s40795-0160049-7.

\section{Publisher's Note}

Springer Nature remains neutral with regard to jurisdictional claims in published maps and institutional affiliations.

Ready to submit your research? Choose BMC and benefit from:

- fast, convenient online submission

- thorough peer review by experienced researchers in your field

- rapid publication on acceptance

- support for research data, including large and complex data types

- gold Open Access which fosters wider collaboration and increased citations

- maximum visibility for your research: over $100 \mathrm{M}$ website views per year

At BMC, research is always in progress.

Learn more biomedcentral.com/submissions 